\title{
Real-World Performance of a Self-Operated Home Monitoring System for Early Detection of Neovascular Age-Related Macular Degeneration
}

\author{
Allen C. Ho ${ }^{1}\left(\mathbb{D}\right.$, Jeffrey S. Heier ${ }^{2}{ }^{\circledR}$, Nancy M. Holekamp ${ }^{3}$, Richard A. Garfinkel ${ }^{4}{ }^{\circledR}$, Byron Ladd $^{5}$, Carl C. Awh ${ }^{6}$, \\ Rishi P. Singh ${ }^{7}$, George E. Sanborn ${ }^{8}$, Jennifer H. Jacobs ${ }^{8}$, Michael J. Elman ${ }^{9}$, Anat Loewenstein 10,11,* \\ and David A. Eichenbaum ${ }^{12}$ (D) \\ Citation: Ho, A.C.; Heier, J.S.; \\ Holekamp, N.M.; Garfinkel, R.A.; \\ Ladd, B.; Awh, C.C.; Singh, R.P.; \\ Wills Eye Hospital, 840 Walnut St., Philadelphia, PA 19107, USA; achomd@gmail.com \\ 2 Ophthalmic Consultants of Boston, 50 Staniford St., Ste. 600, Boston, MA 02114, USA; jsheier@eyeboston.com \\ Pepose Vision Institute, 1815 Clarkson Road, Chesterfield, MO 63124, USA; nholekamp@gmail.com \\ The Retina Group of Washington, 110 Irving St NW, Washington, DC 20010, USA; rgarfinkel@rgw.com \\ Virginia Eye Institute, 6946 Forest Ave Suite 100, Richmond, VA 23230, USA; laddb@vaeye.com \\ Tennessee Retina, 345 23rd Avenue North, Suite 350, Nashville, TN 37203, USA; carlawh@gmail.com \\ 7 Center for Ophthalmic Bioinformatics, Cole Eye Institute, Cleveland Clinic Foundation, 9500 Euclid Avenue, \\ i-32, Cleveland, OH 44106, USA; singhr@ccf.org \\ 8 Notal Vision, 7717 Coppermine Dr., Manassas, VA 20109, USA; georges@notalvision.com (G.E.S.); \\ jjacobs@notalvision.com (J.H.J.) \\ 9 Elman Retina, 7671 Quarterfield Rd \#100, Glen Burnie, MD 21061, USA; elman@elmanretina.com \\ 10 Department of Ophthalmology, Tel Aviv Medical Center, Tel Aviv 6209105, Israel \\ 11 The Sackler Faculty of Medicine, Tel Aviv University, Tel Aviv 6997801, Israel \\ 12 Retina Vitreous Associates of Florida, 4344 Central Ave, St. Petersburg, FL 33711, USA; \\ deichenbaum@rvaf.com \\ * Correspondence: anatl@tlvmc.gov.il
} Sanborn, G.E.; Jacobs, J.H.; Elman, M.J.; et al. Real-World Performance of a Self-Operated Home Monitoring System for Early Detection of Neovascular Age-Related Macular Degeneration. J. Clin. Med. 2021, 10, 1355. https://doi.org/10.3390/ jcm10071355

Academic Editor: Laurent Kodjikian

Received: 9 February 2021

Accepted: 19 March 2021

Published: 25 March 2021

Publisher's Note: MDPI stays neutral with regard to jurisdictional claims in published maps and institutional affiliations.

Copyright: (c) 2021 by the authors. Licensee MDPI, Basel, Switzerland. This article is an open access article distributed under the terms and conditions of the Creative Commons Attribution (CC BY) license (https:// creativecommons.org/licenses/by/ $4.0 /)$.
Abstract: The real-world performance of a home telemonitoring strategy (ForeseeHome AMD Monitoring System ${ }^{\circledR}$, Notal Vision, Inc.,Manassas VA, USA) was evaluated and compared to the device arm of the AREDS2-HOME study among patients with intermediate AMD (iAMD) who converted to neovascular AMD (nAMD). All patients with confirmed conversion to nAMD who used the home monitoring system from 10/2009 through 9/2018 were identified by Notal Vision Diagnostic Clinic's medical records. Selected outcome variables were evaluated, including visual acuity (VA) at baseline and at conversion, and change in visual acuity (VA) from baseline to time of conversion. In total, 8991 patients performed 3,200,999 tests at a frequency of $5.6 \pm 3.2$ times/week. The 306 eyes that converted from iAMD to nAMD over the study period (a $2.7 \%$ annual rate) were included in the analyses. There was a median (interquartile range) change of $-3.0(0.0-(-10.0))$ letters among converted eyes, 81\% [95\% confidence interval (72-88\%)] maintained a VA $\geq 20 / 40$ at the time of conversion, while $69 \%$ of the conversion detections were triggered by system alerts. The real-world performance of an at-home testing strategy was similar to that reported for the device arm of the AREDS2-HOME study. The home telemonitoring system can markedly increase early detection of conversion to nAMD.

Keywords: ForeseeHome AMD Monitoring System ${ }^{\circledR}$; neovascular age-related macular degeneration; AREDS2-HOME study

\section{Introduction}

Eyes with early and intermediate age-related macular degeneration (AMD) typically retain good central vision and overall vision [1]. Any subsequent vision loss is usually attributed to advanced AMD, specifically, geographic atrophy or neovascular AMD (nAMD). Both the Comparison of AMD Treatments Trial (CATT) [2,3] and a real-world analysis that employed the Intelligent Research in Sight (IRIS) registry [4] confirmed that baseline visual 
acuity (VA) at the time of conversion from AMD to nAMD is a strong predictor of long-term visual outcomes under treatment with intravitreal anti-vascular endothelial growth factor (anti-VEGF) therapies. Significant visual improvement with these treatments, as shown in the landmark registration studies [5-7], is often not replicated in real-world outcome studies. Given that baseline vision is a strong determinant of long-term visual outcome and that long-term gains in vision are often unsustainable, early detection of nAMD can be pivotal to achieving favorable therapeutic results [8-11]. A recent cost-utility analysis reported that early treatment was $138-149 \%$ more cost-effective than late treatment, and those authors concluded that early treatment is critical for obtaining optimal vision and cost-effectiveness, as is long-term follow-up and adherence to treatment [12].

Despite the obvious benefit of detecting conversion to nAMD while vision is still good, many reports reveal that only 13 to $35 \%$ of patients are diagnosed and begin intravitreal antiVEGF treatment when their VA is $20 / 40$ or better [4,13-15]. One analysis of IRIS registry data on 13,859 subjects found that the mean VA at conversion to nAMD was 20/74 [4]. In another and larger IRIS database analysis, the mean VA of more than 140,000 newly converted eyes was 20/83 [14,15]. Similar findings of poor VA at conversion have been widely reported in other studies in which VA at the time of conversion ranged from 20/80 to $20 / 142$ [16-22].

The incidence of conversion from dry to nAMD [13,14,23-25] suggests that frequent monitoring of eyes with intermediate AMD would be optimal. However, bringing a large, older population into clinics for monitoring visual and anatomic changes can be difficult for both the patient and the caregivers, particularly given current safety concerns related to the COVID-19 pandemic. One possible solution to address these difficulties is at-home self-monitoring. Patients and physicians have long used the Amsler grid as a home monitoring strategy, but it has limited efficacy due to factors, such as problems in filling in the information, lack of fixation, and poor compliance [26,27]. No well-designed clinical trial has shown that the Amsler grid is effective in detecting nAMD in patients with good VA. More effective types of home monitoring technologies and services may well have increasing relevance and desirability in a COVID-19 environment and beyond, as people may prefer to "stay at home" to limit their potential exposure to the virus [28].

The AREDS2-HOME study [29,30] evaluated one home self-monitoring strategy that included the ForeseeHome AMD monitoring system (Notal Vision, Inc., Manassas, VA, USA). The system uses preferential hyperacuity perimetry to detect minute differences in the relative spatial localization of two or more objects and was previously described [1]. In brief, during the test of each eye, the patient is responding to fast stimuli in random locations in the visual field of the central $14^{\circ}$. These flashing signals include artificial distortions with varying amplitudes. The marking of the patient in the location of the presented distortion, in a different location, or the absence of a response are collected, transmitted to the secured cloud location, and are analyzed by the system's artificial intelligence algorithm. Upon identification of a statistically significant change in the testing results compared to a baseline period, a change alert is communicated to the prescribing physician through a remote diagnostic clinic that provides the monitoring service. The study randomized subjects to either a device arm that included the home monitoring system in addition to standard care or to a control arm that included standard care alone. The study findings showed that a significantly higher percentage of patients were able to maintain VA of 20/40 or better after using the strategy that included home monitoring to help identify conversion in early stages.

The objective of this study was to evaluate the performance in real-world implementation of the strategy that includes the use of this at-home monitoring system in combination with standard care, i.e., the strategy implemented in the device arm of the HOME study. The system allows the patients to proactively monitor their visual status between doctor visits while at the same time establishing a safety net that is intended to prevent significant loss of vision during the conversion to nAMD. This evaluation focused on the most relevant parameters of vision preservation. We hypothesized that since the real-world implementation uses the same device, hyperacuity test, remote diagnostic clinic infrastructure, and 
compliance reminder services all integrated into a monitoring program, then the efficacy of the system would be similar to the efficacy reported by the participants randomized to the device arm of the AREDS2-HOME study.

\section{Patients and Methods}

This is a retrospective review of data on all patients with available information on a confirmed conversion from intermediate AMD to nAMD during their participation in an at-home monitoring program any time during the period from October 2009 through September 2018. The inclusion criteria for enrollment into the program was diagnosis of intermediate dry AMD and best corrected visual acuity of 20/60 or better in any eye that was prescribed. Participation was defined as having a device at home and the availability of a valid baseline. Patients were identified from the medical records of the Notal Vision Diagnostic Clinic (Notal Vision Inc.; Manassas, VA USA), an independent diagnostic testing facility and medical provider of the home monitoring program. Patients were referred to the program by an eyecare professional. Upon referral, the NVDC contacted the patient over the telephone, provided explanations about the nature of the disease and the purposes of the device, and shipped the device to the patient's home. Following remote training on device operation, the patients established a baseline of testing results. They were instructed and encouraged to self-test daily. The NVDC monitored their compliance to these instructions and reminded patients to self-test when necessary. Artificial intelligence compared the patient's baseline and most recent sequence of testing results to a normative database and transmitted the information to the NVDC. If there had been a statistically significant change from baseline in recent self-test scores (an alert), a notification was sent to the NVDC. After the alert was reviewed by the NVDC, it was relayed to the referring physician's office staff who contacted the patient to schedule a clinical evaluation. Other complementary triggers for an in-office visit were routine and symptoms visits. All these visit-triggering modalities jointly comprise the home monitoring strategy under evaluation.

This study was granted an exemption of oversight by an independent institutional review board (IntegReview, Austin, TX, USA) on the basis of Code of Federal Regulations Title 45, Part 46.104. It does not contain any human participants or use of animals.

\subsection{Outcome Variables}

The datasets of eyes with reported conversion during the study period included demographics, overall duration of participation in the monitoring program (as reported in monitoring years as the sum of periods from the first test to the reported conversion of all the study eyes), the number of tests performed during the study period and the mean weekly frequency of testing, the annual observed conversion rates, and the dates of identification of conversion to nAMD confirmed by the treating physicians. They also included the VA at baseline and confirmed conversion (when available) as measured at the physician's office, and the modality that triggered the in-office visit in which the diagnosis was confirmed following a system alert (as opposed to detection of conversion during routine or symptom-driven visits).

For the purposes of this study, baseline was defined as the point in time when the patient was first prescribed the at-home monitoring system. The testing baseline used by the system in the ongoing monitoring may have been established few days or weeks later due to the delay from enrollment at the clinic to device delivery, setup, and first usage. Outcome measures included the time from baseline to the reported conversion, the proportion of conversions to nAMD detected following an alert by the at-home monitoring system vs. conversions reported as having been identified during an office visit, the VA at baseline and at the time of conversion, the numerical change in VA from baseline to conversion, the percentage of eyes with a VA $\geq 20 / 40$ at time of conversion, and the percentage of eyes with a VA $\geq 20 / 40$ at baseline that maintained a VA $\geq 20 / 40$ at the time of conversion to nAMD. Conversion was confirmed based on the evaluation of nAMD by a retina specialist. 


\subsection{Statistical Analyses}

Statistical analyses were primarily limited to descriptive statistics with comparison between sub-cohorts when applicable. VA was reported as Snellen equivalent and converted to Early Treatment Diabetic Retinopathy Study (ETDRS) letters for comparison when applicable and reported in letter changes or Snellen [31].

\section{Results}

During the study period, a total of 8991 patients were enrolled in the program and tested a total of 13,930 eyes, representing an average of 1.55 eyes per patient. They performed 3,200,999 tests during 11,525 years of monitoring. A total of 306 eyes were reported to have converted from intermediate AMD to nAMD during the study period representing a conversion rate of $2.7 \%$ per year, and they were included in the current analyses. The mean ( \pm standard deviation, $S D)$ weekly frequency of testing per eye and per patient were $3.7 \pm 1.9$ and $5.6 \pm 3.2$, respectively (Figure 1 ). The patients' mean age was $75 \pm 7.1$ years, and $199(65 \%)$ were females (Table 1). Of the 306 eyes with confirmed disease progression, $211(69 \%)$ were identified following the at-home system alert, and the remaining $95(31 \%)$ were identified during a routine or a symptom-driven visit. The duration from time of baseline to conversion to nAMD by the alerting modality is shown in Table 1. The median 5.7-month difference in the time from baseline to conversion between the modalities was not significant $(p=0.082)$, although it did show a trend towards shorter duration for the system alerts.

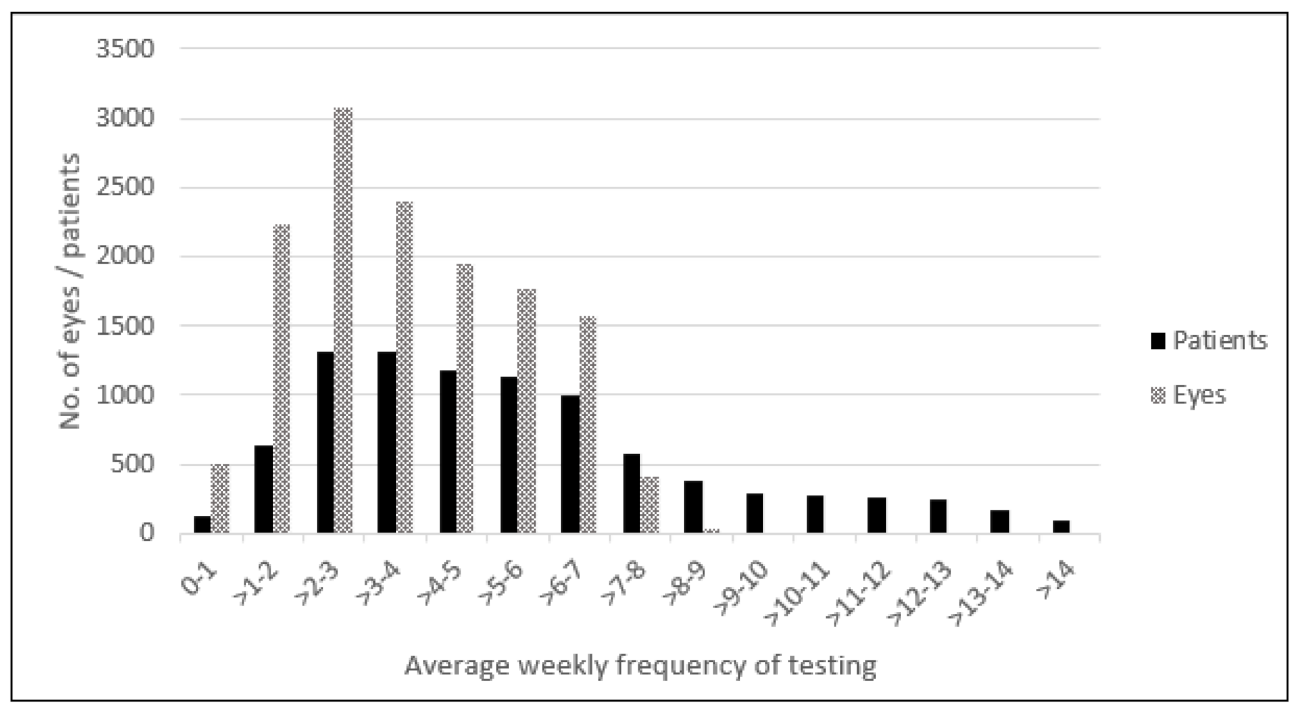

Figure 1. Distribution of the average weekly frequency of testing per eye and per patient.

Table 2 provides details about the VA for the entire cohort and by detection modality. The data included the VA at baseline, at conversion to NAMD, and the change in VA from baseline. Since this report is based on real-world, retrospectively collected data, not all VA values from both time points were available. There was a statistically significant difference in visual acuity between baseline and at the time of conversion $(p=0.00014)$. The mean (SD) and median (interquartile range, IQR) change in VA from baseline to conversion for the 121 eyes with data at both time points was $-5.4(10.0)$ and $-3.0[0.0-(-10.0)]$, respectively. For the 95 eyes with VA data that was triggered by system alert, the change in VA from baseline to conversion was a median (IQR) of $-2[0.0-(-10.0)]$ letters. In comparison, the change in VA from baseline to conversion in the 26 eyes where the conversion was detected during routine or symptom-driven office visits was a median (IQR) of -4.5 [0.0-(-16.5] letters. The difference of 2.5 letters in median change of VA was not statistically significant $(p=0.19)$. 
Table 1. Demographics and time to conversion from AMD to nAMD of patients in the at-home monitoring program by modality of detection.

\begin{tabular}{|c|c|c|c|}
\hline $\begin{array}{c}\text { Modality of Detection, } n(\%) \\
\text { of Conversions }\end{array}$ & All Conversions: $306(100 \%)$ & $\begin{array}{c}\text { Conversion Detected } \\
\text { Following an Alert: } \\
211(69 \%)\end{array}$ & $\begin{array}{c}\text { Conversion Detected during } \\
\text { Routine or Symptom-driven } \\
\text { Visit to Physician } \\
95(31 \%)\end{array}$ \\
\hline Mean age in years (SD) & $75(7.1)$ & $76(6.9)$ & $73(7.3)$ \\
\hline Female sex, $n$ & $199(65 \%)$ & $139(66 \%)$ & $60(63 \%)$ \\
\hline $\begin{array}{c}\text { Mean (SD) time from } \\
\text { initiation of the at-home } \\
\text { device use to conversion, } \\
\text { months }\end{array}$ & $16.8(16.3)$ & $15.8(15.4)$ & $19.2(18.0)$ \\
\hline $\begin{array}{l}\text { Median (IQR) time from } \\
\text { initiation of the at-home } \\
\text { device use to conversion, } \\
\text { months }\end{array}$ & $11.4(4.3-23.5)$ & $10.5(3.9-22.3)$ & $16.2(5.4-24.2)$ \\
\hline
\end{tabular}

AMD: age-related macular degeneration; nAMD: neovascular age-related macular degeneration; SD: standard deviation; IQR: interquartile range.

Table 2. Visual acuity outcomes by detection modality.

\begin{tabular}{|c|c|c|c|c|}
\hline VA Outcomes & Baseline VA & $\begin{array}{c}\text { VA at Conversion to } \\
\text { nAMD }\end{array}$ & $\begin{array}{l}\text { VA at Conversion with } \\
\text { Known Baseline VA }\end{array}$ & $\begin{array}{c}\text { VA Change from } \\
\text { Baseline to } \\
\text { Conversion }\end{array}$ \\
\hline No. of eyes & 121 & 193 & 121 & \\
\hline Mean VA [SD] letters & $77.7(7.4)$ & $72.4(12.0)$ & $72.3(12.7)$ & $-5.46(10.0)$ \\
\hline Mean VA Snellen & $20 / 32$ & $20 / 40$ & $20 / 40$ & \\
\hline $\begin{array}{l}\text { Median VA [IQR] } \\
\text { letters }\end{array}$ & $79.0(74.0-84.0)$ & $75.0(68.0-81.0)$ & $74.0(66.0-81.0)$ & $-3.0(0.0-(-10.0))$ \\
\hline Median VA Snellen & $20 / 25$ & $20 / 32$ & $20 / 32$ & \\
\hline \multicolumn{5}{|c|}{ Eyes with nAMD detection triggered by a system alert with known VA } \\
\hline No. of eyes & 95 & 151 & 95 & \\
\hline Mean VA [SD] letters & $77.6(7.1)$ & 72.7 (11.2) & $73.1(11.3)$ & $-4.5(8.6)$ \\
\hline Mean VA, Snellen & $20 / 32$ & $20 / 40$ & $20 / 40$ & \\
\hline $\begin{array}{l}\text { Median VA [IQR] } \\
\text { letters }\end{array}$ & $78.0(74.0-83.0)$ & $75.0(69.0-81.0)$ & $74.0(68.5-81.0)$ & $-2.0(0.0-(-10.0))$ \\
\hline Median VA Snellen & $20 / 32$ & $20 / 32$ & $20 / 32$ & \\
\hline
\end{tabular}

Eyes with nAMD detection during a routine or symptom-driven visit to physician with known VA

\begin{tabular}{ccccc}
\hline No. of eyes & 26 & 42 & 26 & $-8.6[13.9]$ \\
\hline Mean VA [SD] letters & $78.0[8.7]$ & $71.3[14.7]$ & $69.4[16.8]$ & $20 / 40$ \\
\hline Mean VA Snellen & $20 / 32$ & $20 / 40$ & $74.0[56.25-82.5]$ & $-4.5[0.0-(-16.5]$ \\
\hline $\begin{array}{c}\text { Median VA [IQR] } \\
\text { letters }\end{array}$ & $81.0[71.75-85.75]$ & $76.0[62.25-81.0]$ & $20 / 32$ \\
\hline Median VA Snellen & $20 / 25$ & $20 / 32$ & \\
\hline
\end{tabular}

VA; visual acuity; AMD: age-related macular degeneration; nAMD: neovascular age-related macular degeneration; SD: standard deviation; IQR: interquartile range.

Of the 193 eyes with information about the VA at conversion to nAMD, the VA of 144 eyes (75\%; $95 \%$ confidence interval, CI [68-81\%]) was equal or better than $20 / 40$. Of the 109 eyes with a baseline VA $\geq 20 / 40,88$ eyes $(81 \%, 95 \%$ CI [72-88\%]) maintained a $\mathrm{VA} \geq 20 / 40$ at the time of conversion and initiation of treatment. Detection was triggered 
by a system alert in 86 eyes with a baseline VA $\geq 20 / 40$ that had information about VA at the time of conversion, and 71 of those eyes (83\%, 95\% CI [73-90\%]) maintained a $\mathrm{VA} \geq 20 / 40$. Seventeen of the 23 eyes with a baseline VA $\geq 20 / 4074 \%$ (95\% CI [52-90\%]) in which conversion was detected during a routine or symptom-driven visit maintained a $V A \geq 20 / 40$. There was no significant difference between the alerting modalities and the proportion of eyes with a VA $\geq 20 / 40(p=0.38)$.

\section{Discussion}

This study reports on the real-world performance of a monitoring strategy that included an at-home self-operated monitoring system in conjunction with office visits (both routine and symptom-driven) for early detection of nAMD. This same strategy was evaluated in a prospective multicenter study that found patients in the home monitoring arm lost significantly less VA from baseline to the time of conversion than those being followed by standard care alone [29].

Our current study included a larger group of eyes $(n=306)$ that converted to nAMD compared to the AREDS2-HOME study $(n=82)$. Our reported conversion rate was $2.7 \%$ per monitoring year, which is typical for an intermediate AMD population [32,33], and provides an indication that a significant portion of conversions within this cohort was captured during the study. The mean (SD) weekly frequency of testing per eye was $3.7 \pm 1.9$, which is consistent with $3.44 \pm 1.86$ tests per week reported in a recent publication on realworld use of the ForeseeHome device [34]. The patients in our study tested themselves $5.6 \pm 3.2$ times per week, consistent with the frequency of 5.9 tests per week as calculated from a recent real-world report, [34] and more than the frequency of $4.4 \pm 1.7$ tests per week reported in the AREDS2-HOME study. A comparison of the distribution of detection between the triggering modalities revealed a similar rate of "first to trigger" by the home monitoring system was reported in both studies: it was $69 \%$ in the current study compared with $64 \%$ in the AREDS2-HOME study in a comparable per protocol (PP1) population of patients who were using the device at the time of nAMD detection, regardless of frequency of use [29]. Our findings suggest that the inclusion of the home monitoring program in an overall monitoring strategy allows the at-home system to detect the majority of disease conversions, thereby providing an effective safety net for patient vision. The median (IQR) change in VA for the entire cohort was -3.0 [0.0-(-10.0)] letters. In comparison, the median (IQR) change in VA for the device arm of the HOME study was very similar, at $-3.0[-1.0-(-10.0)]$ letters [29].

Our study demonstrated that $81 \%$ [95\% CI (72-88\%)] of eyes with a VA $\geq 20 / 40$ at baseline retained that vision at the time of conversion, which was lower than the $91 \%$ reported for a comparable group in the device arm of the HOME study, but higher than the $62 \%$ reported in the control arm of the HOME study [29]. The current report also showed a much higher percentage of eyes with a VA of $\geq 20 / 40$ (75\%) at the time of conversion to $\mathrm{nAMD}$ when all eyes were considered, other real-world studies of newly diagnosed nAMD reported a percentage of eyes with a VA of 20/40 or better at the time of conversion that ranged from 13.1 to $34.3 \%$, [14,16,35,36] notably including the IRIS registry dataset ( $n=55,930$ eyes), in which $34.3 \%$ of eyes had a VA $\geq 20 / 40$ at the time of diagnosis [14]. Caution is recommended when interpreting these comparative data, however, since the population that elects to use a home monitoring technology does not necessarily represent the general population included in the IRIS database. Our current study showed that for this population, which is similar to the PP1 population in the AREDS2-HOME study, there was real-world efficacy in identifying patients with a better vision at the time of conversion through the use of an at-home monitoring system, a finding comparable to the results of the AREDS2-HOME study.

Overall, there was no significant difference between the alerting modalities in terms of the VA in eyes with good vision $(>20 / 40)$ at the time of conversion in this population. One possible explanation for the different outcomes of the current and IRIS studies may be that the HOME study baseline VA was 83 letters on the ETDRS chart while it was 79 letters 
in the current study, shifting the distribution of VAs below the threshold of 20/40. Another possible explanation is that the group of patients who converted to nAMD in this paper who elected to use a home-monitoring technology were more sensitive to small subjective changes in vision, than the IRIS population.

The main limitation of this study is that it is a retrospective database analysis. The VA was not available at baseline or at conversion for all patients, and some of the VA values were reported over the telephone, which may have introduced some bias. This review only included patients who converted to nAMD after establishing a baseline on the ForeseeHome monitoring system. In trying to evaluate the sensitivity of the findings to possible methodological limitations resulting from the retrospective, real-world study design, we considered a worst-case scenario in which an unbalanced, larger number of events were triggered by routine visits or symptoms that were not identified and therefore not included in the report, and we found the expected VA loss to be 4.5 letters. Another limitation is that we did not collect information about the outcomes of alerts issued by the home monitoring system that did not result in an immediate identification of conversion to nAMD. These may include alerts that led to conversions to nAMD that were identified after some delay, alerts that led to the diagnosis of non-nAMD pathologies, and those that wound up being false alerts. In some instances, the patient re-established a baseline and resumed testing. However, those limitations were mitigated by study strengths, which include the length of review (9 years) and the very large number of tests and monitoring years. Also, the same system was used in both the real-world and the AREDS2-HOME study, with the same support and reminders as reflected in the high weekly frequency of use. This allowed us to avoid some of the typical difference between studies and real-world evidence. Other strengths were the uniquely large number of newly diagnosed nAMD events that were detected early after a period of close follow-up with the ForeseeHome system, which differs from how a typical cohort of treatment-naïve nAMD eyes are traditionally diagnosed, treated, and reported during an office visit.

Our conclusions differ from those of another recently published real-world data set, [36] primarily because the reports evaluated two different populations of real-world patients. The current study evaluated a patient population that had a device with a valid baseline up to and including the time of conversion. Yu et al. [34] evaluated all patients who were prescribed the device, and they cite a large number of patients who did not or could not establish or re-establish a baseline, as well as a considerable number of patients who discontinued use of the device.

In conclusion, our current study suggests that the consistent long-term use of an at-home monitoring system may provide a significant benefit to patients as a means of increasing early detection of nAMD with good vision, a known strong predictor for long-term preservation of vision $[13,14]$. AMD has been long established as a common condition in the elderly population [37]. In today's COVID-19 pandemic environment and beyond, the ability to provide quality care to patients at high risk of converting to nAMD while limiting their potential exposure to COVID-19 bestows additional value. This study provides evidence to demonstrate that an at-home monitoring system can achieve those goals. It may drive physicians, patients, and their families to request access, gain benefit from the expected performance, and drive a large-scale improvement in the quality of life of this growing population.

Author Contributions: Conceptualization, G.E.S. and J.H.J.; methodology, G.E.S. and J.H.J.; writingoriginal draft preparation, A.C.H., G.E.S., and J.H.J.; writing-review and editing, A.C.H., J.S.H., N.M.H., R.A.G., B.L., C.C.A., R.P.S., G.E.S., J.H.J., M.J.E., A.L., and D.A.E. All authors have read and agreed to the published version of the manuscript.

Funding: Sponsorship for this study and Rapid Service Fee were funded by Notal Vision, Inc.

Institutional Review Board Statement: This article is based on a retrospective review and does not contain any studies with human participants or animals performed by any of the authors. 
Informed Consent Statement: Patient consent was waived due to the separation between the source data and case report forms in this retrospective study.

Data Availability Statement: The datasets generated and analyzed during the current study are not publicly available since the data could be used to derive business intelligence information about the company that owns the clinical data and considers them confidential.

Acknowledgments: The information reported in the manuscript was presented at the Virtual ASRS 2020 (July 2020) and at the Virtual Retina Society 2020 (September 2020).

Conflicts of Interest: Allen C. Ho is a consultant and has received study grants from Notal Vision, Inc.; Jeffrey S. Heier is a consultant for Notal Vision, Inc; Nancy Holekamp is a consultant for Notal Vision, Inc.; Richard A. Garfinkel has no financial disclosures relevant to this publication; Byron Ladd is a consultant for Notal Vision; Carl Awh has an equity interest in Notal Vision, Inc.; Rishi Singh receives research grant funding from Aerie, Apellis, and Graybug; Consultant for Alcon, Bausch and Lomb, Genentech, Regeneron, Novartis, and Zeiss; George E. Sanborn is an employee of Notal Vision, Inc.; Jennifer H. Jacobs is an employee of Notal Vision, Inc.; Michael J. Elman is a consultant and has received study grants from Notal Vision, Inc.; Anat Loewenstein is a consultant for Notal Vision; David A. Eichenbaum is a consultant for Notal Vision, Inc.

Author Contributions: All named authors meet the International Committee of Medical Journal Editors (ICME) criteria for authorship for this article, take responsibility for the integrity of the work as a whole, and have given their approval for this version to be published.

\section{References}

1. AREDS-HOME Study Research, Group; Chew, E.Y.; Clemons, T.; Bressler, S.B.; Elman, M.J.; Danis, R.P.; Domalpally, A.; Garfinkel, R.A. Randomized trial of the ForeseeHome monitoring device for early detection of neovascular age-related macular degeneration. The HOme Monitoring of the Eye (HOME) study design (HOME Study report number 1). Contemp. Clin. Trials. 2014, 37, 294-300. [CrossRef]

2. Ying, G.S.; Huang, J.; Maguire, M.G.; Jaffe, G.J.; Grunwald, J.E.; Toth, C.; Daniel, E.; Klein, M.; Pieramici, D.; Wells, J.; et al. Baseline predictors for one-year visual outcomes with ranibizumab or bevacizumab for neovascular age-related macular degeneration. Ophthalmology 2013, 120, 122-129. [CrossRef] [PubMed]

3. Rao, P.; Lum, F.; Wood, K.; Salman, C.; Burugapalli, B.; Hall, R.; Singh, S.; Parke, D.W., 2nd; Williams, G.A. Real-World Vision in Age-Related Macular Degeneration Patients Treated with Single Anti-VEGF Drug Type for 1 Year in the IRIS Registry. Ophthalmology 2018, 125, 522-528. [CrossRef] [PubMed]

4. Brown, D.M.; Kaiser, P.K.; Michels, M.; Soubrane, G.; Heier, J.S.; Kim, R.Y.; Sy, J.P.; Schneider, S.; ANCHOR Study Group. Ranibizumab versus verteporfin for neovascular age-related macular degeneration. N. Engl. J. Med. 2006, 355, 1432-1444. [CrossRef]

5. Heier, J.S.; Brown, D.M.; Chong, V.; Korobelnik, J.F.; Kaiser, P.K.; Nguyen, Q.D.; Kirchhof, B.; Ho, A.; Ogura, Y.; Yancopoulos, G.D.; et al. Intravitreal aflibercept (VEGF trap-eye) in wet age-related macular degeneration. Ophthalmology 2012, 119, 2537-2548. [CrossRef] [PubMed]

6. $\quad$ Rosenfeld, P.J.; Brown, D.M.; Heier, J.S.; Boyer, D.S.; Kaiser, P.K.; Chung, C.Y.; Kim, R.Y.; MARINA Study Group. Ranibizumab for neovascular age-related macular degeneration. N. Engl. J. Med. 2006, 355, 1419-1431. [CrossRef]

7. Comparison of Age-related Macular Degeneration Treatments Trials Research Group; Maguire, M.G.; Martin, D.F.; Ying, G.S.; Jaffe, G.J.; Daniel, E.; Grunwald, J.E.; Toth, C.A.; Ferris, F.L., 3rd; Fine, S.L. Five-Year Outcomes with Anti-Vascular Endothelial Growth Factor Treatment of Neovascular Age-Related Macular Degeneration: The Comparison of Age-Related Macular Degeneration Treatments Trials. Ophthalmology 2016, 123, 1751-1761. [CrossRef]

8. Rofagha, S.; Bhisitkul, R.B.; Boyer, D.S.; Sadda, S.R.; Zhang, K.; Group S-US. Seven-year outcomes in ranibizumab-treated patients in ANCHOR, MARINA, and HORIZON: A multicenter cohort study (SEVEN-UP). Ophthalmology 2013, 120, 2292-2299. [CrossRef]

9. Mehta, H.; Tufail, A.; Daien, V.; Lee, A.Y.; Nguyen, V.; Ozturk, M.; Barthelmes, D.; Gillies, M.C. Real-world outcomes in patients with neovascular age-related macular degeneration treated with intravitreal vascular endothelial growth factor inhibitors. Prog. Retin. Eye Res. 2018, 65, 127-146. [CrossRef]

10. Evans, R.N.; Reeves, B.C.; Phillips, D.; Muldrew, K.A.; Rogers, C.; Harding, S.P.; Chakravarthy, U.; IVAN Study Group. Long-term Visual Outcomes after Release from Protocol in Patients who participated in the Inhibition of VEGF in Age-related choroidal Neovascularisation (IVAN) Trial. Ophthalmology 2020, 127, 1191-1200. [CrossRef]

11. Brown, G.C.; Brown, M.M.; Rapuano, S.; Boyer, D. Cost-Utility Analysis of VEGF-Inhibitors for Treating Neovascular Age-Related Macular Degeneration. Am. J. Ophthalmol. 2020, 218, 225-241. [CrossRef]

12. Ho, A.C.; Albini, T.A.; Brown, D.M.; Boyer, D.S.; Regillo, C.D.; Heier, J.S. The Potential Importance of Detection of Neovascular Age-Related Macular Degeneration When Visual Acuity Is Relatively Good. JAMA Ophthalmol. 2017, 135, 268-273. [CrossRef] [PubMed] 
13. Ho, A.C. Retrospective Analysis of Real-World Disease Detection and Visual Acuity Outcomes in Patients with Dry AMD Converting to Wet AMD Using the AAO IRIS Registry Database. In Proceedings of the 2018 ASCRS ASOA Annual Meeting, Washington, DC, USA, 13-17 April 2018.

14. Kim, J.E. Real-World Analysis of Injection Frequency Following nAMD Diagnosis According to Baseline Visual Acuity. In Proceedings of the Macula Society, Bonita Springs, FL, USA, 13-16 February 2019.

15. Fong, D.S.; Custis, P.; Howes, J.; Hsu, J.W. Intravitreal bevacizumab and ranibizumab for age-related macular degeneration a multicenter, retrospective study. Ophthalmology 2010, 117, 298-302. [CrossRef]

16. Lee, A.Y.; Lee, C.S.; Butt, T.; Xing, W.; Johnston, R.L.; Chakravarthy, U.; Egan, C.; Akerele, T.; McKibbin, M.; Downey, L.; et al. UK AMD EMR USERS GROUP REPORT V: Benefits of initiating ranibizumab therapy for neovascular AMD in eyes with vision better than 6/12. Br. J. Ophthalmol. 2015, 99, 1045-1050. [CrossRef]

17. Rayess, N.; Houston, S.K.; Gupta, O.P., 3rd; Ho, A.C.; Regillo, C.D. Treatment outcomes after 3 years in neovascular age-related macular degeneration using a treat-and-extend regimen. Am. J. Ophthalmol. 2015, 159, 3-8. [CrossRef] [PubMed]

18. Keenan, T.D.; Kelly, S.P.; Sallam, A.; Mohamed, Q.; Tufail, A.; Johnston, R.L. Incidence and baseline clinical characteristics of treated neovascular age-related macular degeneration in a well-defined region of the UK. Br. J. Ophthalmol. 2013, 97, 1168-1172. [CrossRef] [PubMed]

19. Cohen, S.Y.; Dubois, L.; Tadayoni, R.; Fajnkuchen, F.; Nghiem-Buffet, S.; Delahaye-Mazza, C.; Guiberteau, B.; Quentel, G. Results of one-year's treatment with ranibizumab for exudative age-related macular degeneration in a clinical setting. Am. J. Ophthalmol. 2009, 148, 409-413. [CrossRef]

20. Hirami, Y.; Mandai, M.; Takahashi, M.; Teramukai, S.; Tada, H.; Yoshimura, N. Association of clinical characteristics with disease subtypes, initial visual acuity, and visual prognosis in neovascular age-related macular degeneration. Jpn J. Ophthalmol. 2009, 53, 396-407. [CrossRef]

21. Zawinka, C.; Ergun, E.; Stur, M. Prevalence of patients presenting with neovascular age-related macular degeneration in an urban population. Retina 2005, 25, 324-331. [CrossRef]

22. Schmidt-Erfurth, U.; Waldstein, S.M.; Klimscha, S.; Sadeghipour, A.; Hu, X.; Gerendas, B.S.; Osborne, A.; Bogunovic, H. Prediction of Individual Disease Conversion in Early AMD Using Artificial Intelligence. Invest. Ophthalmol. Vis. Sci. 2018, 59, 3199-3208. [CrossRef]

23. Friberg, T.R.; Bilonick, R.A.; Brennen, P.M. Risk factors for conversion to neovascular age-related macular degeneration based on longitudinal morphologic and visual acuity data. Ophthalmology 2012, 119, 1432-1437. [CrossRef]

24. McGuinness, M.B.; Finger, R.P.; Wu, Z.; Luu, C.D.; Chen, F.K.; Arnold, J.J.; Chakravarthy, U.; Guymer, R. Association between Patient-Reported Outcomes and Time to Late Age-Related Macular Degeneration in the Laser Intervention in Early Stages of Age-Related Macular Degeneration Study. Ophthalmol. Retin. 2020, 4, 881-888. [CrossRef] [PubMed]

25. Loewenstein, A.; Malach, R.; Goldstein, M.; Leibovitch, I.; Barak, A.; Baruch, E.; Alster, Y.; Rafaeli, O.; Avni, I.; Yassur, Y. Replacing the Amsler grid: A new method for monitoring patients with age-related macular degeneration. Ophthalmology 2003, 110, 966-970. [CrossRef]

26. Chamard, C.; Lacombe, S.; Navarre, S.; Rohart, C.; Daures, J.P.; Allieu, S. Is current age related macular degeneration selfmonitoring a good tool for detecting exudative recurrence? J. Fr. Ophtalmol. 2019, 42, 1049-1055. [CrossRef] [PubMed]

27. Hsiang, S.; Allen, D.; Annan-Phan, S.; Bell, K.; Bolliger, I.; Chong, T.; Druckenmiller, H.; Huang, L.Y.; Hultgren, A.; Krasovich, E.; et al. The effect of large-scale anti-contagion policies on the COVID-19 pandemic. Nature 2020, 584, 262-267. [CrossRef] [PubMed]

28. Kim, J.E. The HOME Study: Lesion characteristics of early choroidal neovascularization. In Proceedings of the American Society of Retina Specialists 2014, San Diego, CA, USA, 9-13 August 2014.

29. Gregori, N.Z.; Feuer, W.; Rosenfeld, P.J. Novel method for analyzing snellen visual acuity measurements. Retina 2010, 30, 1046-1050. [CrossRef]

30. Bressler, N.M.; Bressler, S.B.; Congdon, N.G.; Ferris, F.L., 3rd; Friedman, D.S.; Klein, R.; Lindblad, A.S.; Milton, R.C.; Seddon, J.M. Potential public health impact of Age-Related Eye Disease Study results: AREDS report no. 11. Arch. Ophthalmol. 2003, 121, 1621-1624.

31. Ferris, F.L.; Davis, M.D.; Clemons, T.E.; Lee, L.Y.; Chew, E.Y.; Lindblad, A.S.; Milton, R.C.; Bressler, S.B.; Klein, R. A simplified severity scale for age-related macular degeneration: AREDS Report No. 18. Arch. Ophthalmol. 2005, 123, 1570-1574. [PubMed]

32. Yu, H.J.; Kiernan, D.F.; Eichenbaum, D.; Sheth, V.S.; Wykoff, C.C. Home Monitoring of Age-Related Macular Degeneration: Real-World Utility of the ForeseeHome Device for Detection of Neovascularization. Ophthalmol. Retina 2020.

33. Acharya, N.; Lois, N.; Townend, J.; Zaher, S.; Gallagher, M.; Gavin, M. Socio-economic deprivation and visual acuity at presentation in exudative age-related macular degeneration. Br. J. Ophthalmol. 2009, 93, 627-629. [CrossRef]

34. Olsen, T.W.; Feng, X.; Kasper, T.J.; Rath, P.P.; Steuer, E.R. Fluorescein angiographic lesion type frequency in neovascular age-related macular degeneration. Ophthalmology 2004, 111, 250-255. [CrossRef] [PubMed]

35. Lim, L.S.; Mitchell, P.; Seddon, J.M.; Holz, F.G.; Wong, T.Y. Age-Related Macular Degeneration. Lancet 2012, $379,1728-1738$. [CrossRef] 
36. Ferris, F.L., 3rd; Fine, S.L.; Hyman, L. Age-Related Macular Degeneration and Blindness Due to Neovascular Maculopathy. Arch. Ophthalmol. 1984, 102, 1640-1642. [CrossRef] [PubMed]

37. Zapata, M.A.; Burés, A.; Gallego-Pinazo, R.; Gutiérrez-Sánchez, E.; Oléñik, A.; Pastor, S.; Abraldes, M. Prevalence of age-related macular degeneration among optometric telemedicine users in Spain: A retrospective nationwide population-based study. Graefe's Arch. Clin. Exp. Ophthalmol. 2021, 1-11. [CrossRef] 